\title{
Granulocyte Colony-Stimulating Factor Enhances the Anticancer Effects of Cisplatin against Lung Cancer by Promoting Angiogenesis
}

\author{
Yun-Mo Li' ${ }^{1}$, Yasushi Ohno ${ }^{*}$, Norihiko Funaguchi' ${ }^{2}$, Takenobu Gomyo', Yuka Sasaki ${ }^{1}$, \\ Sayaka Toyoshi', Daizo Kaito', Komei Yanase1, Junki Endo1, Fumitaka Ito1, Masanori Kawasaki', \\ Shinya Minatoguchi1
}

${ }^{1}$ Department of Cardiology and Respirology, Graduate School of Medicine, Gifu University, Gifu, Japan

${ }^{2}$ Department of Respiratory Medicine, Murakami Memorial Hospital, Asahi University, Mizuho, Japan

Email: *yasusi@gifu-u.ac.jp

How to cite this paper: Li, Y.-M., Ohno, Y., Funaguchi, N., Gomyo, T., Sasaki, Y., Toyoshi, S., Kaito, D., Yanase, K., Endo, J., Ito, F., Kawasaki, M. and Minatoguchi, S. (2017) Granulocyte Colony-Stimulating Factor Enhances the Anticancer Effects of Cisplatin against Lung Cancer by Promoting Angiogenesis. Advances in Lung Cancer, 6, $1-11$.

https://doi.org/10.4236/alc.2017.61001

Received: February 7, 2017

Accepted: March 28, 2017

Published: March 31, 2017

Copyright (๑) 2017 by authors and Scientific Research Publishing Inc. This work is licensed under the Creative Commons Attribution International License (CC BY 4.0).

http://creativecommons.org/licenses/by/4.0/ (c) (i) Open Access

\begin{abstract}
The G-CSF is used as a therapeutic drug of the febrile neutropenia in lung cancer chemotherapy, however, there were few reports that showed the effects of combination effects of G-CSF and anticancer drugs against lung cancer. In the present study, we investigated the effects of G-CSF and the combination effects of G-CSF and cisplatin on lung cancer growth. We investigated the effect of G-CSF against the LL-2 and KLN-205 cells by MTT assay and tried to detect the G-CSF receptor by RT-PCR. Next, to analyze the G-CSF effects in vivo, we transplanted the LL-2 into C57BL/6 mice, intraperitoneally administered G-CSF (30 micro/kg/day) with or without cisplatin $(5 \mathrm{mg} / \mathrm{kg}$ ), measured the tumor size and analyzed pathologically by $\mathrm{HE}$ and immunostaining. In vitro analyses, G-CSF showed no effects in LL-2 and KLN-205 cells, and RTPCR revealed no G-CSF receptor mRNA. In vivo analyses, G-CSF alone did not significantly suppress tumor growth. However, concurrent G-CSF administration with cisplatin significantly enhanced the tumor suppressing effect of cisplatin in early stage of tumor growth. The analysis data of vWF immunostaining indicated that the neovascularization in the peripheral region of the tumors was more enhanced in G-CSF treatment mice. ELISA assay revealed that G-CSF did not influence the serum concentration of TNF-alpha and IL12 in tumor-bearing mice. This study suggests that concurrent (combination) administration of cisplatin with G-CSF is a safe and effective method for enhancing anticancer effects and reducing chemotherapeutic agent-induced myelosuppression.
\end{abstract}




\section{Keywords}

Granulocyte Colony-Stimulating Factor, Lung Cancer, G-CSF Receptor, Angiogenesis, Anticancer Agent, Cisplatin, TNF-Alpha, IL-12

\section{Introduction}

Cytokine granulocyte colony-stimulating factor (G-CSF) is a hematopoietic growth factor which enhances the proliferation and differentiation of neutrophil precursor cells [1]. In addition, it stimulates a variety of responses in peripheral blood neutrophils including phagocytosis, superoxide production and chemotaxis [2]. G-CSF is clinically used to enhance the recovery of the number and function of neutrophils during chemotherapy-induced neutropenia in various hematogenous and nonhematogenous malignant and nonmalignant diseases [3] [4] [5] [6] [7]. However, the results of studies on G-CSF-induced tumor growth are controversial. Recently, some studies reported that G-CSF stimulates the growth of tumor cells such as colon cancer cells [8], small lung cancer cells [9], skin carcinoma cells and astrocytoma cells [10] [11], In contrast, Brandstetter et al. reported that G-CSF does not exhibit any effect on the proliferation of ovarian carcinoma cell lines or tumor samples despite presence of the G-CSF receptor in the tested cell lines and biopsies [12]. Moreover, G-CSF inhibits tumor growth in a B16-BL6 melanoma cell transplanted mice model [13]. However, none of these studies were conducted using concurrent administration with anticancer agents. G-CSF as an adjuvant with cytotoxic chemotherapeutic agent in cancer chemotherapy is very important to clarify its effects on tumor growth in combination with anticancer agents. Thus, to further elucidate the role of GCSF in tumor growth, especially in combination with anticancer drugs, we used one of the most useful clinical anticancer drug cisplatins (CDDP) [14] [15] [16] [17], whose most serious side effect is bone marrow suppression [18] [19] [20], concurrently administered with G-CSF in a transplanted lung cancer cells mouse model, and the possible mechanism responsible for the effects of G-CSF on tumor growth was studied in vitro and in vivo.

\section{Materials and Methods}

\subsection{In Vitro Effects of G-CSF on Tumor Cell Proliferation}

The effect of G-CSF on tumor growth in vitro was determined by 3-[4,5-dimethylthiazol-2yl]-2,5-diphenyl-tetrazolium (MTT) assay as previously described [21] [22] [23] [24]. Two mouse non-small lung cancer cell lines, Lewis lung cancer cell line (LL-2) and KLN-205 (Japanese Collection of Research Bioresources Cell Bank, Ibaraki, Japan) were grown in DMEM medium with $10 \%$ fetal bovine serum (FBS). One hundred microliters of $1.0 \times 10^{5}$ cells $/ \mathrm{ml}$ cells per well were seeded in 96-multiwell plates and precultured for 24 hours. Thereafter, the cells were stimulated without (control) or with various concentrations of G-CSF sup- 
plements with 2\% FBS for 48 hours. Each experiment was performed in triplicates, and the results were expressed as the relative viability percentage as follows:

Relative viability percentage $=($ mean OD560nm for the G-CSF test $/$ without G-CSF control) $\times 100 \%$.

RNA isolation and reverse transcription polymerase chain reaction (RT-PCR) for G-CSF receptor mRNA detection.

Bone marrow cells isolated from a normal six weeks-old male C57BL/6 mouse as previously described [25] were used as a positive control for G-CSF receptor mRNA. Total RNA was extracted from cultured LL-2 and KLN-205 cells as well as from unseparated bone marrow cells using Isogene (Nippongene, Chiyoda$\mathrm{ku}$, Japan), and 3 microg of the total RNA was subjected to a reverse transcription reaction using a First Strand cDNA Synthesis kit (Amersham Biosciences Corp., Piscataway, NJ) according to the manufacture's instructions. After reverse transcription, the cDNA was subjected to the following PCR reaction: (a) the beta-actin-specific $967 \mathrm{bp}$ fragment was detected by PCR $\left(25\right.$ cycles at $94^{\circ} \mathrm{C}$ for 1 $\min , 60^{\circ} \mathrm{C}$ for $1 \mathrm{~min}$, and $72^{\circ} \mathrm{C}$ for $2 \mathrm{~min}$ ) using the primers

5'-GTGACGAGGCCCAGAGCAAGAG-3' (sense) and

5'-AGGGGCCGGACTCATCGTACTC-3' (anti-sense); (b) the G-CSF receptorspecific $567 \mathrm{bp}$ fragment was detected by PCR $\left(38\right.$ cycles at $94^{\circ} \mathrm{C}$ for $1 \mathrm{~min}, 65^{\circ} \mathrm{C}$ for $1 \mathrm{~min}$, and $72^{\circ} \mathrm{C}$ for $1 \mathrm{~min}$ ) with the primers

5'-CCСCTCAAACCTATCCTGCCTC-3' (sense) and 5'-TCCAGGCAGAGATCAGCGAATG-3' (anti-sense) [26]. The negative PCR reactions control contained water instead of DNA template. To eliminate artifacts, RT-PCR was performed at least three times.

\subsection{In Vivo Evaluation of the Effects of G-CSF on Tumor Growth}

Seven week-old male C57BL/6 mice were purchased from CLEA Japan (Meguro$\mathrm{ku}$, Japan). LL-2 cancer cells were grown in culture, harvested and subcutaneously injected as a suspension $\left(1.0 \times 10^{5}\right.$ cells in $0.1 \mathrm{ml}$ of serum-free medium) into the $\mathrm{C} 57 \mathrm{BL} / 6$ mice in the proximal dorsa midline. The mice were randomized into 4 groups (ten mice in each group), group 1) saline control, 2) G-CSF alone, 3) CDDP alone and 4) CDDP plus G-CSF group. The mice were injected $5 \mathrm{mg} / \mathrm{kg}$ CDDP intraperitoneally 2 hours after tumor cell transplantation and then, were given $5 \mathrm{mg} / \mathrm{kg}$ CDDP intraperitoneally each week. Two hours after CDDP or saline injection, the mice were given 30 micro/kg G-CSF or the same volume of saline intraperitoneally each day, and 21 days after tumor cell transplantation they were sacrificed and the tumors were removed. To investigate the mechanism responsible for G-CSF activity on tumor growth, twelve mice were transplanted LL-2 tumor cells $\left(1.0 \times 10^{5}\right.$ cells $\left./ 0.1 \mathrm{ml}\right)$ and divided equally two groups. One group was injected $30 \mathrm{micro} / \mathrm{kg} \mathrm{G}-\mathrm{CSF}$ and the other was injected the same volume of saline each day and 7 days after treatment they were sacrificed and the tumors were removed. Excised tumor specimens were fixed in 10\% buffered formalin, and tumor size was measured along the longest superficial 
diameter (a) and smallest superficial diameter (b), and tumor volume expressed as: $\mathrm{a} \times \mathrm{b} 2 \times 0.52\left(\mathrm{~mm}^{3}\right)$.

\subsection{Evaluation of Microvessel Density}

Sections 4 micro $m$ thick which were taken 7 days after tumor cell transplantation were de-paraffinized and incubated with anti-von Willebrand factor (vWF) rabbit antibody (DAKO Cytomation Co. Ltd., Kyoto, Japan). Immunolabelling was performed using an avidin-biotin-peroxidase technique (Vectastain $A B C$ kit, Vector Laboratories, Burlingame, CA) followed by counterstaining with hematoxylin, and negative control slides were obtained by omitting the primary antibody. Microvessels were identified by positive staining for vWF and morphology. The individual different fields for each tissue preparation, and microvessel density were expressed as the total microvessel count in the ten fields.

\subsection{Determination of Cytokines Present in Mice Serum}

Serum levels of tumor necrosis factor alpha (TNF-alpha) and interleukin-12 (IL-12) were measured 21 days after tumor cells transplantation. Under ether anesthesia mice were bled $4 \mathrm{~h}$ after the last G-CSF injection, and the levels of TNF-alpha and IL-12 in serum samples were determined using ELISA kits (BioSource International, Inc. Camarillo, CA). Each assay was performed according to the manufacture's instructions. The sensitivity of the TNF-alpha and IL-12 ELISA kits are $3.0 \mathrm{pg} / \mathrm{ml}$ and $2.0 \mathrm{pg} / \mathrm{ml}$, respectively. All samples and standards were run in duplicate.

\subsection{Statistical Analysis}

The data was expressed as the mean $\pm \mathrm{SD}$. P values were calculated using the Student's t-test, and $\mathrm{p}<0.05$ was considered to be statistically significant.

\section{Results}

\subsection{In Vitro Effect of G-CSF on Tumor Growth}

In vitro effect of G-CSF on tumor cell proliferation and the absence of G-CSF receptor mRNA in lung cancer cells.

The direct effect of G-CSF on tumor cell proliferation was determined by MTT assay in two mouse cell lines. We found that LL-2 and KLN-205 cell proliferation was unchanged significantly in the presence of various concentrations of G-CSF (Figure 1). To ensure that the results were due to the absence of the GCSF receptor, we investigated the G-CSF receptor mRNA in these two cell lines by RT-PCR. A 567 bp fragment of G-CSF receptor mRNA was detected only in unseparated bone marrow cells (positive control), and was not detected in these two cell lines (Figure 2).

\subsection{In Vivo Effect of G-CSF on Tumor Growth}

Next, to evaluate the effects of G-CSF on lung cancer in vivo, we studied the tumor growth in lung cancer-bearing mice model treated with G-CSF and also in 


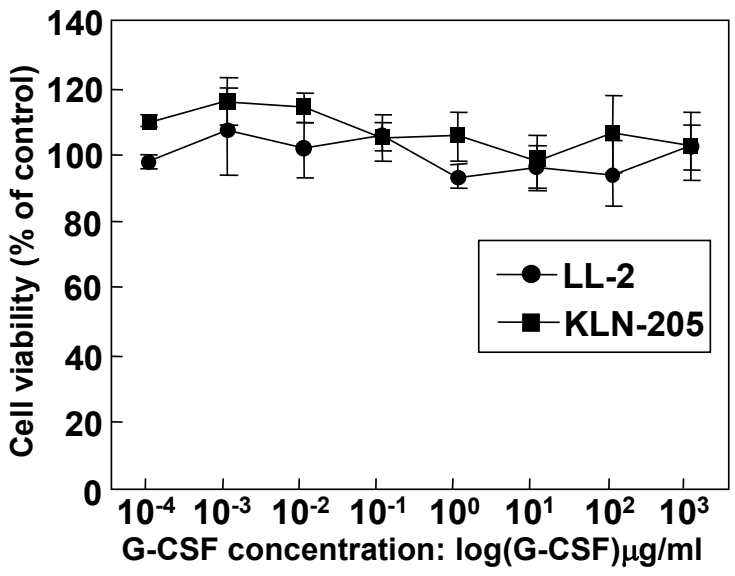

Figure 1. Examination of the in vitro lung cancer cell proliferation. The cultured cell is cultured with G-CSF of various kinds of density, and the cell proliferation is examined in MTT assay and is displayed in percent.

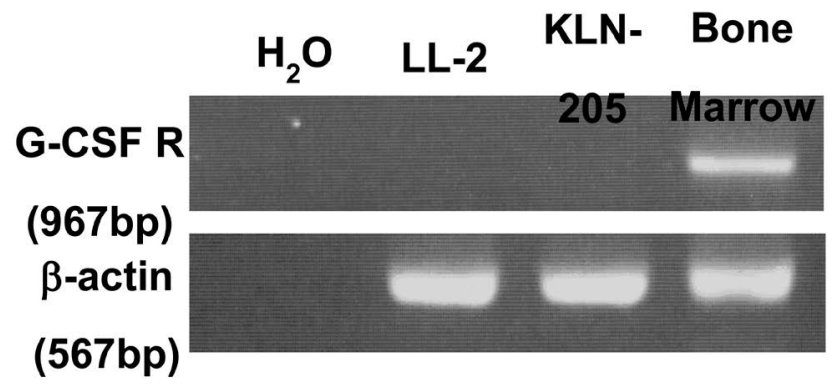

Figure 2. Detection of G-CSF receptor mRNA by RT-PCR. The presence of $567 \mathrm{bp}$ fragment indicates G-CSF receptor mRNA. Positive control: unseparated murine bone marrow cell. Murine lung cancer cell lines LL-2 and KLN-205 could not detect G-CSF receptor mRNA. $\beta$-actin mRNA (967bp) was detected in all tested cell lines.

vestigated the combination effects of G-CSF and cisplatin the latter of which is commonly used in chemotherapy of lung cancer. In a previous study, six of ten mice died at $10 \mathrm{mg} / \mathrm{kg}$ CDDP and no mice died at $5 \mathrm{mg} / \mathrm{kg}$ CDDP. Thus, the maximum tolerable dose (MTD) was regarded as being close to $5 \mathrm{mg} / \mathrm{kg}$. Groups of mice were intraperiotoneally given $5 \mathrm{mg} / \mathrm{kg}$ CDDP or saline per week starting 2 hours after tumor cell transplantation. Then, 2 hours after CDDP or saline injection the mice were intraperitoneally given $30 \mathrm{micro} / \mathrm{kg}$ G-CSF or saline per day. Tumor growth was markedly inhibited in the CDDP and CDDP+G-CSF treatment group compared with the saline control group. Concurrent administration of G-CSF significantly enhanced the tumor suppressing effect of CDDP in early stage tumor growth. 7 days after tumor cells transplantation, the tumor volume were $6.84 \pm 9.07$ for CDDP plus G-CSF treatment VS $16.34 \pm 10.29 \mathrm{~mm}^{3}$ for CDDP alone $(\mathrm{p}=0.047)$ (Figure 3 ).

\subsection{Mechanism of the Effectiveness}

To evaluate the effect of G-CSF on tumor-associated angiogenesis, immunostaining for vWF, an established endothelial cell marker, was performed. As 
shown in Figure 4, in tumors from mice 7 days after G-CSF treatment, vessels were usually found in the actively proliferating peripheral region of the tumors, whereas the middle tumor parenchyma showed scant vessel distribution. In contrast, tumors from the control mice showed only few vessels even in peripheral tumor tissues $(53.2 \pm 5.3$ versus $35.4 \pm 3.7) \mathrm{p}<0.05$.

Recent papers reported that G-CSF modulates the balance between Th1 and Th2 cells and down-regulates the Th1 driving cytokine [27] [28], so, we studied the representative Th1 cytokine, TNF-alpha and IL-12. The concentrations of TNF- $\alpha$ and IL-12 in the serum of tumor-bearing mice were estimated using ELISA. As shown in Figure 5, there was no statistically significant difference for

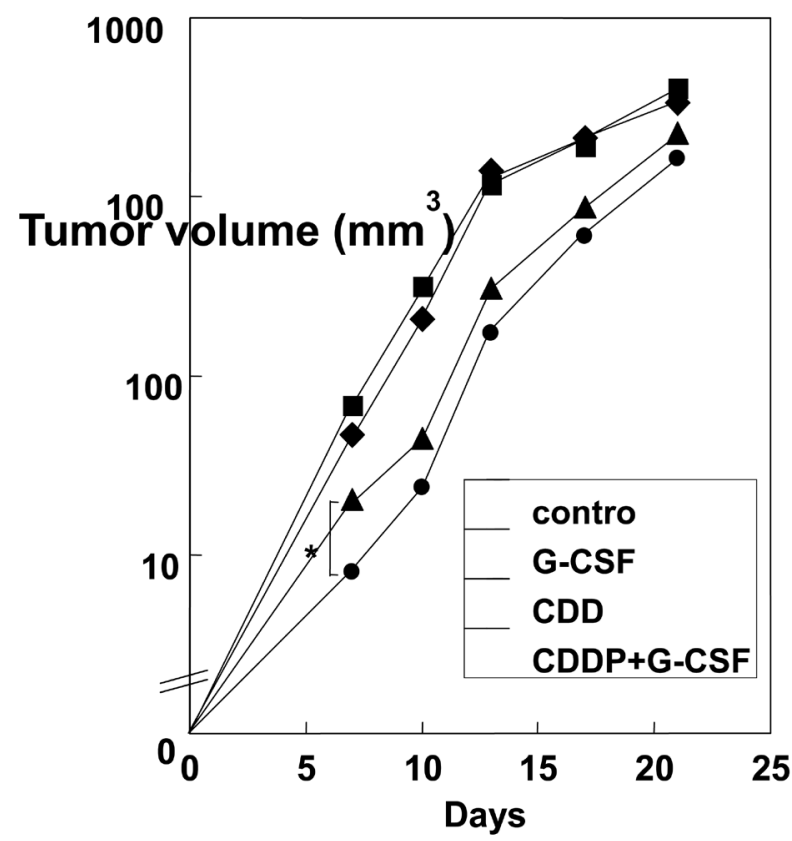

Figure 3. Effect of treatment with G-CSF and CDDP on growth of lewis lung (LL-2) carcinoma. Tumor size was measured by calipers on the longest superficial diameter (a) and smallest superficial diameter (b) Tumor volume was expressed as a $\times$ b2 $\times 0.52 \mathrm{~mm}^{3}$. Filled diamond: saline, filled square: G-CSF treatment, filled triangle: CDDP treatment and filled circle: $\mathrm{G}+\mathrm{C}(\mathrm{G}-\mathrm{CSF}$ and CDDP) treatment.

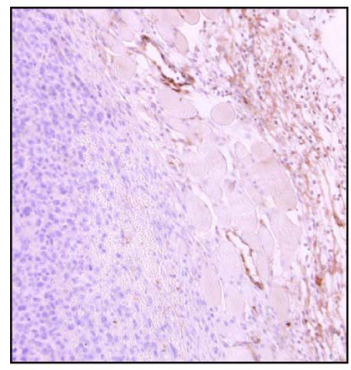

Contro

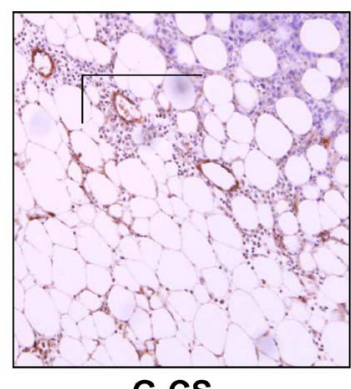

G-CS

(a)

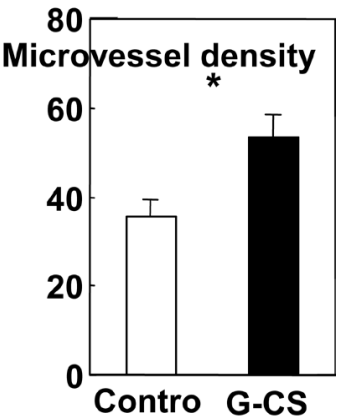

(b)

Figure 4. Effects of G-CSF on tumor angiogenesis. (a) The blood vessels were stained with vWF antibody $(\times 100)$; (b) Microvessel density was assessed in the highest staining for vWF positive area in ten fields. ${ }^{*}<0.05$. 


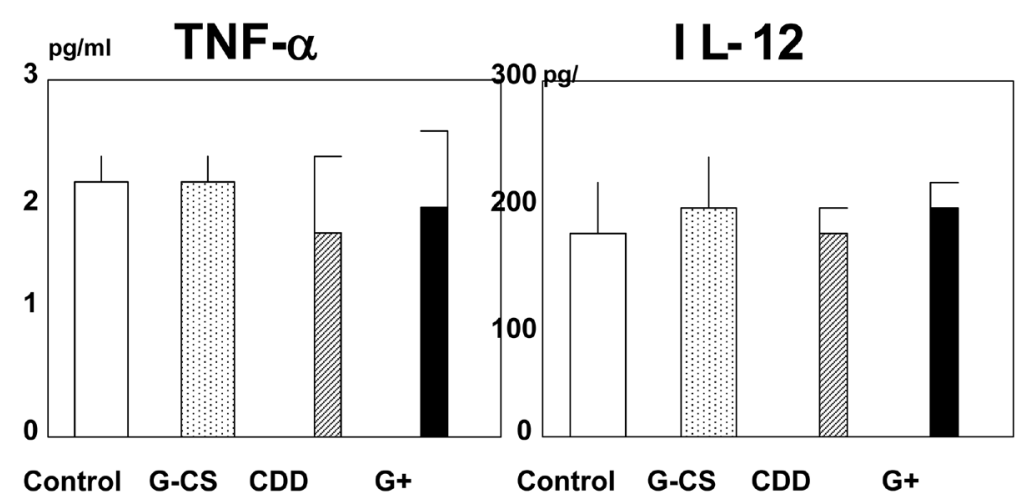

Figure 5. Serum concentration of TNF-alpha and IL-12. The serum concentration of TNF-aand IL-12 that were taken from 21 days after drugs treatment. White column.

the IL-12 and TNF- $\alpha$ concentrations in serum taken 21 days after drug treatment among the 4 groups $(\mathrm{p}>0.05)$.

\section{Discussion}

\subsection{Influence on Cancer Increase of the G-CSF}

Generally, the hematopoietic growth factors are widely used for neutrophil recovery during chemotherapy in solid tumors, and there were few reports whether these growth factors affect solid tumor growth and they compromise anticancer drug effects. In the present study, the effects of G-CSF on lung cancer growth were investigated. We found that the murine non-small lung cancer cell lines LL-2 and KLN-205 were not affected by G-CSF treatment in vitro. Moreover, RT-PCR revealed the absence of G-CSF receptor mRNA, suggesting that G-CSF has no direct effect on the growth of these lung cancer cell lines due to the absence of the G-CSF receptor. For in vivo studies, G-CSF alone did not alter tumor growth, whereas concurrent administration of G-CSF with CDDP significantly enhanced the tumor suppressing effect of CDDP in early stage tumor growth. CDDP is cytotoxic agent and a key drug in the chemotherapy of lung cancer. It is generally accepted that cytotoxicity of CDDP is mediated through induction of apoptosis and arrest of cell cycle resulting from its interaction with DNA, such as the formation of CDDP-DNA adducts, which activates multiple signaling pathways, including those involving p53, Bcl-2 family, caspase, cyclins, MAPK and PI3K/Akt [29] [30] [31].

\subsection{Mechanism of the Effectiveness}

To determine the mechanisms responsible for the enhanced effect of tumor growth inhibition for concurrent administration of G-CSF with CDDP, we focused on the effect of G-CSF on tumor-associated angiogenesis as measured by vWF immunostaining, and found that treatment with G-CSF significantly enhanced tumor neovascularization. Bussolino et al. showed that G-CSF stimulates DNA synthesis followed by the endothelial cell proliferation [32], and Natori et al. showed that bone marrow-derived endothelial progenitor cells play a role in 
enhanced tumor angiogenesis in an implanted colon cancer cell mouse model [33]. So, we also considered that G-CSF promotes the angiogenesis by stimulating DNA synthesis of endothelial cell and mobilizing bone marrow-derived endothelial progenitor cells. As the reason of the enhanced anticancer effect by addition of G-CSF, we thought that the enhancement of tumor neovascularization by addition of G-CSF increased the concentration and the exposure time of CDDP within tumor in early stage. And in late stage, the tumor neovascularization did not occur inside of tumor and the concentration of CDDP inside tumor was thought to be very low, so the significant difference of the tumor size was not seen between CDDP group and CDDP + G-CSF group.

It is recently reported that G-CSF has the function not only to mobilize the hematopoietic stem cells but also to immunomodulate the balance between $\mathrm{T}$ helper 1 (Th1) and T helper 2 (Th2) cells in favor of Th2 cells [27] [28] [34] [35]. In the present study, we did not detect the significant difference of TNF-alpha and IL-12 concentrations in serum taken 21 days after drug treatment among the 4 groups. As the reason of discrepancy between our data and past report, we thought the character of C57BL/6 mice, which has Th1 dominant immune system and concentration and duration of G-CSF treatment, but it is not clear for this reason of discrepancy and more research must be needed.

\subsection{Limit of This Study}

It is necessary for the limit of this study to examine the increase of cancer when I used other anticancer agents and anticancer agents in future in the examination of the increase of the cancer cell when the G-CSF used it together not taking effect and G-CFS together.

In summary, our results provide evidence that G-CSF as a growth factor does not promote tumor cell proliferation. Concurrent (Combination) administration of G-CSF significantly enhances the tumor suppressing effect of CDDP in early stage tumor growth. Thus, concurrent (combination) administration of G-CSF with anticancer agents is a safe and effective method for reducing chemotherapeutic agent-induced myelosuppression. Although further studies are required to determine whether this effect of G-CSF is a common feature against lung cancer and the solid tumors of the other organs, in this time, our study suggested a novel importance of G-CSF treatment against cancer therapy.

This study was supported by a Grant-in-Aid for Scientific Research (C) from the Japan Society for the Promotion of Science.

Cisplatin was kindly provided from Nippon Kayaku Co. Ltd.

\section{References}

[1] Demetri, G.D. and Griffin, J.D. (1991) Granulocyte Colony-Stimulating Factor and Its Receptor. Blood, 78, 2791-2808.

[2] Asano, S. (1991) Human Granulocyte Colony-Stimulating Factor: Its Basic Aspects and Clinical Applications. American Journal of Pediatric Hematology/Oncology, 13, 400-413. https://doi.org/10.1097/00043426-199124000-00004 
[3] Kuritzkes, D.R. (2000) Neutropenia, Neutrophil Dysfunction, and Bacterial Infection in Patients with Human Immunodeficiency Virus Disease: The Role of Granulocyte Colony-Stimulating Factor. Clinical Infectious Diseases, 30, 256-260. https://doi.org/10.1086/313642

[4] Banerjea, M.C. and Speer, C.P. (2002) The Current Role of Colony-Stimulating Factors in Prevention and Treatment of Neonatal Sepsis. Seminars in Neonatology, 7, 335-349. https://doi.org/10.1053/siny.2002.0116

[5] Bohlius, J., Reiser, M., Schwarzer, G., et al. (2003) Impact of Granulocyte ColonyStimulating Factor (CSF) and Granulocyte-Macrophage CSF in Patients with Malignant Lymphoma: A Systematic Review. British Journal of Haematology, 122, 413 423. https://doi.org/10.1046/j.1365-2141.2003.04450.x

[6] Azoulay, E. and Delclaux, C. (2004) Is There a Place for Granulocyte Colony-Stimulating Factor in Non-Neutropenic Critically Ill Patients? Intensive Care Medicine, 30, 10-17. https://doi.org/10.1007/s00134-003-2049-8

[7] Berliner, N., Horwitz, M. and Loughran, T.P. (2004) Congenital and Acquired Neutropenia. Hematology. American Society of Hematology. Education Program, 63-79. https://doi.org/10.1182/asheducation-2004.1.63

[8] Berdel, W.E., Danhauser-Riedl, S., Steinhauser, G., et al. (1989) Various Human Hematopoietic Growth Factors (Interleukin-3, GM-CSF, G-CSF) Stimulate Clonal Growth of Nonhematopoietic Tumor Cells. Blood, 73, 80-83.

[9] Avalos, B.R., Gasson, J.C., Hedvat, C., et al. (1990) Human Granulocyte ColonyStimulating Factor: Biologic Activities and Receptor Characterization on Hematopoietic Cells and Small Cell Lung Cancer Cell Lines. Blood, 75, 851-857.

[10] Mueller, M.M. and Fusenig, N.E. (1999) Constitutive Expression of G-CSF and GM-CSF in Human Skin Carcinoma Cells with Functional Consequence for Tumor Progression. International Journal of Cancer, 83, 780-789. https://doi.org/10.1002/(SICI)1097-0215(19991210)83:6<780::AID-IJC14>3.0.CO;2$\underline{\mathrm{C}}$

[11] Kikuchi, T., Nakahara, S. and Abe, T. (1996) Granulocyte Colony-Stimulating Factor (G-CSF) Production by Astrocytoma Cells and Its Effect on Tumor Growth. Journal of Neuro-Oncology, 27, 31-38. https://doi.org/10.1007/BF00146081

[12] Brandstetter, T., Ninci, E., Bettendorf, H., et al. (2001) Granulocyte Colony-Stimulating Factor (G-CSF) Receptor Gene Expression of Ovarian Carcinoma Does Not Correlate with G-CSF Caused Cell Proliferation. Cancer, 91, 1372-1383. https://doi.org/10.1002/1097-0142(20010401)91:7<1372::AID-CNCR1141>3.0.CO;2 $-\mathrm{E}$

[13] Matsumoto, Y., Saiki, I., Murata, J., et al. (1991) Recombinant Human Granulocyte Colony-Stimulating Factor Inhibits the Metastasis of Hematogenous and NonHematogenous Tumors in Mice. International Journal of Cancer, 49, 444-449. https://doi.org/10.1002/ijc.2910490323

[14] Cosaert, J. and Quoix, E. (2002) Platinum Drugs in the Treatment of Non-SmallCell Lung Cancer. British Journal of Cancer, 87, 825-833.

https://doi.org/10.1038/sj.bjc.6600540

[15] Vansteenkiste, J., Vandebroek, J., Nackaerts, K., et al. (2003) Influence of CisplatinUse, Age, Performance Status and Duration of Chemotherapy on Symptom Control in Advanced Non-Small Cell Lung Cancer: Detailed Symptom Analysis of a Randomised Study Comparing Cisplatin-Vindesine to Gemcitabine. Lung Cancer, 40, 191-199.

[16] Ramalingam, S. and Belani, C.P. (2004) State-of-the-Art Chemotherapy for Advanced Non-Small Cell Lung Cancer. Seminars in Oncology, 31, 68-74. 
https://doi.org/10.1053/j.seminoncol.2003.12.017

[17] Socinski, M.A. (2004) Cytotoxic Chemotherapy in Advanced Non-Small Cell Lung Cancer: A Review of Standard Treatment Paradigms. Clinical Cancer Research, 10, 4210s-4214s. https://doi.org/10.1158/1078-0432.CCR-040009

[18] Waterhouse, D.M., Reynolds, R.K. and Natale, R.B. (1993) Combined Carboplatin and Cisplatin. Limited Prospects for Dose Intensification. Cancer, 71, 4060-4066. https://doi.org/10.1002/1097-0142(19930615)71:12<4060::AID-CNCR2820711242> 3.0.CO;2-0

[19] Kurihara, N., Kubota, T., Hoshiya, Y., et al. (1996) Pharmacokinetics of Cis-Diamminedichloroplatinum (II) Given as Low-Dose and High-Dose Infusions. Journal of Surgical Oncology, 62, 135-138. https://doi.org/10.1002/(SICI)1096-9098(199606)62:2<135::AID-JSO10>3.0.CO;2-7

[20] Miyanaga, N. and Akaza, H. (2001) Verify the Optimum Administration of Anticancer Agent-Cisplatin. Gan To Kagaku Ryoho, 28, 1339-1344.

[21] Mosmann, T. (1983) Rapid Colorimetric Assay for Cellular Growth and Survival: Application to Proliferation and Cytotoxicity Assays. Journal of Immunological Methods, 65, 55-63.

[22] Ohno, Y., Fukuda, K., Takemura, G., et al. (1999) Induction of Apoptosis by Gallic Acid in Lung Cancer Cells. Anticancer Drugs, 10, 845-851. https://doi.org/10.1097/00001813-199910000-00008

[23] Kawada, M., Ohno, Y., Li, Y., et al. (2001) Anti-Tumor Effect of Gallic Acid on LL-2 Lung Cancer Cells Transplanted in Mice. Anticancer Drugs, 12, 847-852. https://doi.org/10.1097/00001813-200111000-00009

[24] Li, Y.M., Ohno, Y., Minatoguchi, S., et al. (2003) Extracts from the Roots of Lindera Strychifolia Induces Apoptosis in Lung Cancer Cells and Prolongs Survival of Tumor-Bearing Mice. The American Journal of Chinese Medicine, 31, 857-869. https://doi.org/10.1142/S0192415X03001545

[25] Krause, D.S., Theise, N.D., Collector, M.I., et al. (2001) Multi-Organ, Multi-Lineage Engraftment by a Single Bone Marrow-Derived Stem Cell. Cell, 105, 369-377.

[26] Schmitt, R.M., Bruyns, E. and Snodgrass, H.R. (1991) Hematopoietic Development of Embryonic Stem Cells in Vitro: Cytokine and Receptor Gene Expression. Genes \& Development, 5, 728-740. https://doi.org/10.1101/gad.5.5.728

[27] Boneberg, E.M., Hareng, L., Gantner, F., et al. (2000) Human Monocytes Express Functional Receptors for Granulocyte Colony-Stimulating Factor That Mediate Suppression of Monokines and Interferon-Gamma. Blood, 95, 270-276.

[28] Sloand, E.M., Kim, S., Maciejewski, J.P., et al. (2000) Pharmacologic Doses of Granulocyte Colony-Stimulating Factor Affect Cytokine Production by Lymphocytes in Vitro and in Vivo. Blood, 95, 2269-2274.

[29] Siddik, Z.H. (2003) Cisplatin: Mode of Cytotoxic Action and Molecular Basis of Resistance. Oncogene, 22, 7265-7279. https://doi.org/10.1038/sj.onc.1206933

[30] Boulikas, T. and Vougiouka, M. (2003) Cisplatin and Platinum Drugs at the Molecular Level. Oncology Reports, 10, 1663-1682.

[31] Wang, G., Reed, E. and Li, Q.Q. (2004) Molecular Basis of Cellular Response to Cisplatin Chemotherapy in Non-Small Cell Lung Cancer. Oncology Reports, 12, 955 965.

[32] Bussolino, F., Wang, J.M., Defilippi, P., et al. (1989) Granulocyte- and GranulocyteMacrophage-Colony Stimulating Factors Induce Human Endothelial Cells to Migrate and Proliferate. Nature, 337, 471-473. https://doi.org/10.1038/337471a0

[33] Natori, T., Sata, M., Washida, M., et al. (2002) G-CSF Stimulates Angiogenesis and 
Promotes Tumor Growth: Potential Contribution of Bone Marrow-Derived Endothelial Progenitor Cells. Biochemical and Biophysical Research Communications, 297, 1058-1061.

[34] Arpinati, M., Green, C.L., Heimfeld, S., et al. (2000) Granulocyte-Colony Stimulating Factor Mobilizes T Helper 2-Inducing Dendritic Cells. Blood, 95, 2484- 2490.

[35] Klangsinsirikul, P. and Russell, N.H. (2002) Peripheral Blood Stem Cell Harvests from G-CSF-Stimulated Donors Contain a Skewed Th2 CD4 Phenotype and a Predominance of Type 2 Dendritic Cells. Experimental Hematology, 30, 495-501.

Submit or recommend next manuscript to SCIRP and we will provide best service for you:

Accepting pre-submission inquiries through Email, Facebook, LinkedIn, Twitter, etc. A wide selection of journals (inclusive of 9 subjects, more than 200 journals)

Providing 24-hour high-quality service

User-friendly online submission system

Fair and swift peer-review system

Efficient typesetting and proofreading procedure

Display of the result of downloads and visits, as well as the number of cited articles Maximum dissemination of your research work

Submit your manuscript at: http://papersubmission.scirp.org/

Or contact alc@scirp.org 